\title{
sciendo
}

CIVIL AND ENVIRONMENTAL ENGINEERING REPORTS

E-ISSN 2450-8594

CEER 2019; 29 (3): 048-059

DOI: $10.2478 /$ ceer-2019-0023

Original Research Article

\section{VIBRATION ANALYSIS OF KENYIR DAM POWER STATION STRUCTURE USING A REAL SCALE 3D MODEL}

\author{
Azizi ARBAIN ${ }^{1}$, Ahmad Zhafran AHMAD MAZLAN ${ }^{1 *}$, \\ Mohd Hafiz ZAWAWI' ${ }^{2}$, Mohd Rashid MOHD RADZI ${ }^{3}$ \\ ${ }^{1}$ School of Mechanical Engineering, Engineering Campus, Universiti Sains Malaysia, \\ 14300 Nibong Tebal, Penang, Malaysia \\ ${ }^{2}$ Department of Civil Engineering, College of Engineering, Universiti Tenaga Nasional, \\ 43000 Kajang, Selangor \\ ${ }^{3}$ TNB Generation Division, Tenaga Nasional Berhad, 59200 Kuala Lumpur
}

\begin{abstract}
In this paper, the vibration analysis in terms of modal and harmonic responses are investigated for the power station structure of Kenyir Dam in Terengganu, Malaysia. Modal analysis is carried out to provide the dynamic characteristics of the power station which includes the natural frequencies and mode shapes. Meanwhile, the harmonic response analysis is performed by applying the force to the structure to obtain the Frequency Response Function (FRF) in certain range of frequencies. A real scale threedimensional (3D) model of the Kenyir Dam power station is constructed using SolidWorks software and imported to ANSYS software for the Finite Element (FE) analysis. A proper boundary condition is taken into consideration to demonstrate the real behaviour of the power station structure. From the results, six most significant natural frequencies and mode shapes including the FRF in all three axes are selected. The highest natural frequency value occurred at $5.4 \mathrm{~Hz}$ with the maximum deflection of $0.90361 \mathrm{~m}$ in the $z$ axis direction. This value is important in order to verify whether the structure can overcome the resonance phenomenon from the external disturbance forces in the future.
\end{abstract}

1* Corresponding author: School of Mechanical Engineering, Engineering Campus, Universiti Sains Malaysia, 14300 Nibong Tebal, Penang, Malaysia, zhafran@usm.my, tel. +6045996368 
Keywords: Modal and harmonic responses, natural frequency, mode shape, Frequency Response Function, Finite Element, dam structure

\section{INTRODUCTION}

Dam is a large civil structure that built to hold back the water and control the water level in the reservoir. Besides, the hydropower type dam is used for generating the clean and renewable electricity which gives a great impact to the human civilisation. Kenyir Dam or Sultan Mahmud Power Station that located in Terengganu, Malaysia is an example of the hydropower type dam. This dam is built based on the earth core rock fill, which has an asymmetrical form in dam axis section [1]. Power station is one of the most important part of the dam structure and usually located at the downstream area of the dam. This structure plays an important role in generating an electricity since the turbine and generator are located here. Water from the upstream will flow through the tunnel and towards the turbine which located in the power station [2]. Due to high location of water entrance, the potential energy of water can be converted into the electrical energy based on law of energy conservation $[2,3]$. According to Kulkarni et al., [4], some important parameters such as hydraulic characteristics and flow of water from upstream as well as downstream need to be studied for the dam structure. Through this study, it is possible to learn the vibration effect and determine the durability level of the structure. Thus, it is necessary to investigate the dynamic characteristics of the dam structure which includes modal and harmonic response analyses. In general, there are two ways to conduct modal and harmonic response analyses using the ANSYS software. Firstly, it can be done in ANSYS APDL workbench and secondly in ANSYS Modal-Harmonic workbench. The second method of using ANSYS Modal-Harmonic workbench is more preferable than ANSYS APDL since the workbench platform is newly developed, faster and more efficient for the interaction between external tools such as CAD software and other systems [5]. In addition, since the ability to model the interaction between geometries or regions are important for running the simulation, ANSYS Modal-Harmonic workbench offered a better contact analysis features [6]. The dynamic analysis of dam structure can be conducted using static and modal analysis, whilst for the dam concrete, foundation and materials are assumed to be homogenous and isotropic with linear-elastic behaviour [7]. General procedure for the response analysis which includes the dynamic effects of water and the flexible foundation movement have been introduced by Chopra and Chakrabarti [8]. Khosravi and Heydari [9] also stated that there are three famous approaches to solve dam structure interaction problems, which are: Westergaard approach, Eulerian approach and Langrangian 
approach. Langrangian approach is the most desirable Finite Element Method (FEM) since in this approach, the fluid behaviour and structure can be expressed in terms of displacements. The compatibility of the nodes interaction and formulation that dealing with the structure deformation make it readily incorporated into a structural analysis [10]. Modal and harmonic analyses can be conducted in ANSYS software using FEM which able to solve complex geometries and dealing with various case studies [11]. This numerical method provide an accurate engineering problem solution by replacing a complicated problem with a simpler one [12]. From this analysis, the dynamic parameters such as stress, strain, pressure and deflection can be obtained which useful for further analysis of the dam structure [13]. Khan and Awari [14] also stated that, from modal analysis, a lot of vibration case studies including the main structure and dam components can be investigated. Through the harmonic analysis, the frequency response function (FRF) can be determined. FRF is the key result from the modal analysis study where it can shows the relationship between excitation input force and deflection output signal of a linear-time-invariant system $[15,16]$. In this study, the vibration characteristics of the Kenyir Dam such as the natural frequencies, mode shapes and FRF are investigated using the modal and harmonic response analyses.

\section{METHODOLOGY}

\subsection{D Modelling of the Dam Power Station}

Power station is one of the important parts in the Kenyir Dam structure. This section attached to the outlet of pressure tunnel and located at the downstream area of the dam. This section consists of main hydropower operational machines (turbine and generator) and office complex. There are four turbines with twenty wicked gates at each turbine to control the flow of water from upstream to downstream. The power station section is mainly built using concrete and reinforcement steel materials. Figure 1 shows the overall view of Kenyir Dam and the close-up view of the power station structure. For this simulation study, a real scale three-dimensional (3D) model of the power station structure is designed using SolidWorks software. Figure 2 shows the 3D model of the power station structure which includes the view from the upstream and downstream. The 3D model is drawn based on the as-built drawing provided by the station with an exact dimension of the real dam structure. 


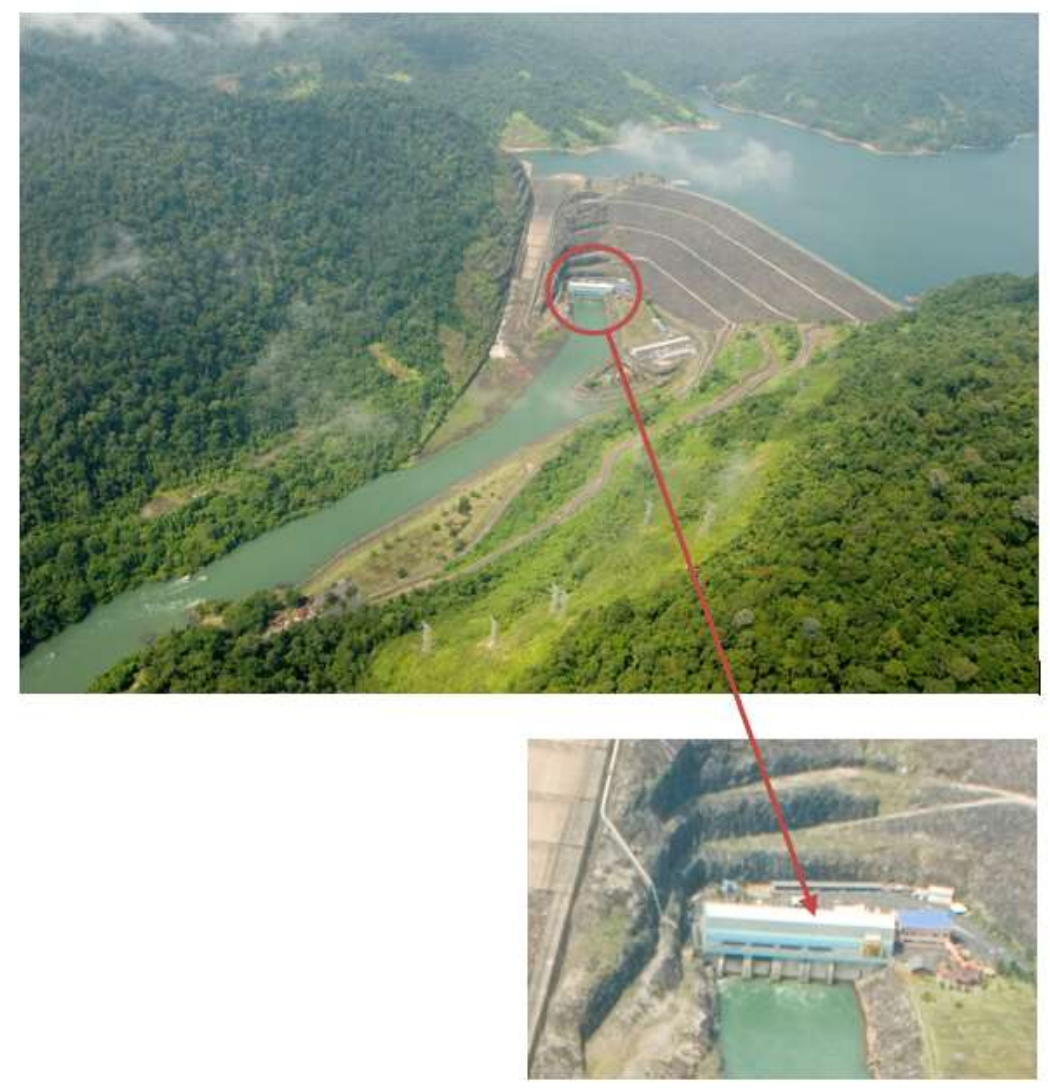

Fig. 1. Overall view of the Kenyir Dam and the close-up view of the power station structure

(a)

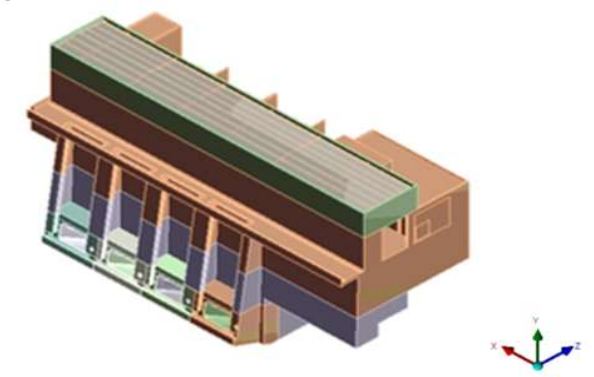

(b)

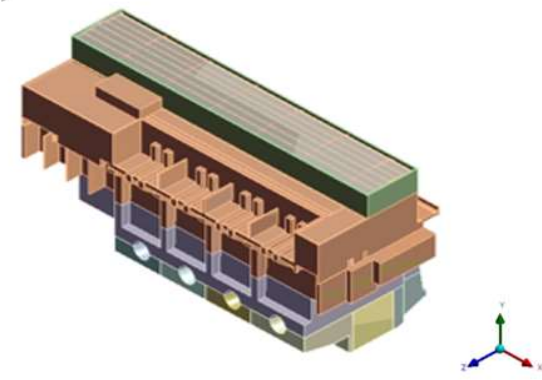

Fig. 2. Isometric view of the 3D model of power station structure: a) upstream view b) downstream view 


\subsection{Construction of Finite Element (FE) Model and Sensitivity Analysis of the Dam Power Station}

The FE model of Kenyir Dam power station is developed using ANSYS software by comprehensively considered the structural feature and boundary condition of the real structure as shown in Figure 3. The boundary condition has been set according to demonstrate the real behaviour of the power station as in the real dam. The base of the power station section is set as fixed support to represent the foundation of the real structure that attached to the earth topography. This model is constructed using two type of materials which are concrete and steel. Concrete material is set for the main building structure while steel is for the reinforcement of the power station. Table 1 shows the detail of concrete and steel material properties that been set in the simulation which includes the density, Young's Modulus and passion ratio. Before performing the simulation, the mesh sensitivity analysis is conducted to investigate the influence of mesh quality to the result of simulation. Through this analysis, an optimum type of meshing can be determined. All three type of meshing which are automatic, hex dominant and tetrahedral are constructed for the FE model of the power station structure. The selection of optimum meshing is based on the most accurate result that been obtained with an appropriate number of elements and shorter computation time. The similar geometry shapes have been used for all three type of meshing to compare their performances.

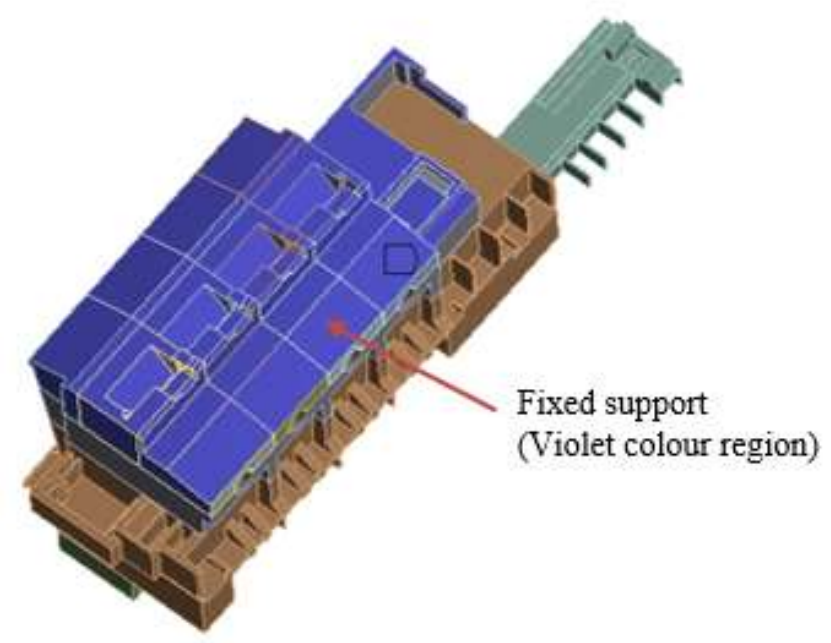

Fig. 3. The FE model with boundary condition of the dam power station 
Table 1. Properties of materials used in FE model for the dam power station

\begin{tabular}{|l|c|c|}
\hline \multirow{2}{*}{\multicolumn{1}{|c|}{ Properties }} & \multicolumn{2}{c|}{ Materials } \\
\cline { 2 - 3 } & Concrete & Steel \\
\hline Density $\left(\mathrm{kgm}^{-3}\right)$ & 2300 & 7850 \\
\hline Young's Modulus $(\mathrm{Pa})$ & $3 \times 10^{10}$ & $2 \times 10^{11}$ \\
\hline Poisson's Ratio & 0.18 & 0.3 \\
\hline
\end{tabular}

\subsection{Modal Analysis (MA) of the Dam Power Station}

The MA of dam power station is conducted using an ANSYS Modal-Harmonic workbench software to study the dynamic properties of the structure. This analysis is performed to determine the vibration characteristics of the structure in terms of natural frequencies, mode shapes and FRF curve. According to the D'Alemberts principle, for most of structural dynamic problems in any systems, the equation of motion in the frequency domain can be expressed by:

$$
\left(-m \omega^{2}+j \omega c+k\right) x(\omega)=F(\omega)
$$

where $m$ is the dynamic mass, $\omega$ is the natural frequency, $c$ is the dynamic damping, $k$ is the dynamic stiffness, $x$ is the output displacement and $F$ is the input force. It can also be expressed as inertance (displacement/force) as in following equation:

$$
\frac{x(\omega)}{F(\omega)}=\frac{1}{\left(-m \omega^{2}+j \omega c+k\right)}
$$

Thus, the natural frequency of the structure is given by:

$$
\omega=\sqrt{\frac{k}{m}}
$$

In this study, the CAD model is firstly designed in SolidWorks software before it is imported to the ANSYS software. The whole power station structure is then set as one part which shared the same topology. The maximum natural frequencies and mode shapes to be find is set to 30 with no frequency limitation search range and six most significant natural frequencies and mode shapes are chosen for the detail discussion.

\section{RESULTS AND DISCUSSION}

\subsection{Meshing Sensitivity Results of the Dam Power Station}

The results of natural frequencies and mode shapes for all three different types of meshing (automatic, hex dominant and tetrahedral) are shown in Table 2. From 
the table, the lowest $1^{\text {st }}$ natural frequency that has been determined is for the hexdominant meshed with $2.4855 \mathrm{~Hz}$ followed by tetrahedral and automatic meshed with $2.5062 \mathrm{~Hz}$ and $2.5501 \mathrm{~Hz}$, respectively. The detail number of nodes and elements for each meshing type is shown in Table 3. From the table, it is realized that, the highest number of nodes and elements is for the tetrahedral meshed with 945834 and 541946 of numbers, respectively. Hex dominant meshed has a slightly smaller number of nodes and elements compared to the tetrahedral meshed with 822629 and 400285 of numbers, respectively. This happened due to shape of hex dominant which is in cube form while for tetrahedral the shape is tetrahedron form. The least number of nodes and element is for the automatic meshed with 560812 and 325068 of numbers, respectively. Figure 4 shows the graph of meshing sensitivity analysis for the power station structure. From the figure, it is proved that the hex dominant has the lowest natural frequency value which indicates this type of meshing is the most optimized. However, in this study, the type of meshing preferred is the tetrahedral due to the complexity shapes and geometries of the power station structure. Using this type of meshing, the error during the simulation can be avoided.

Table 2. The comparison of results between type of meshing and natural frequencies

\begin{tabular}{|c|c|c|c|}
\hline $\begin{array}{l}\text { Meshing } \\
\text { Type }\end{array}$ & Meshed Body & $\begin{array}{l}1^{\text {st }} \text { Natural } \\
\text { Frequency }\end{array}$ & Mode Shapes \\
\hline Automatic & & $2.5501 \mathrm{~Hz}$ & \\
\hline $\begin{array}{l}\text { Hex } \\
\text { Dominant }\end{array}$ & & $2.4855 \mathrm{~Hz}$ & \\
\hline $\begin{array}{l}\text { Tetrahedra } \\
1\end{array}$ & & $2.5062 \mathrm{~Hz}$ & \\
\hline
\end{tabular}


Table 3. Detail of meshing type and corresponding number of nodes and elements

\begin{tabular}{|c|c|c|}
\hline Meshing Type & No. of Nodes & No. of Elements \\
\hline Automatic & 560812 & 325068 \\
\hline Hex Dominant & 822629 & 400285 \\
\hline Tetrahedral & 945834 & 514946 \\
\hline
\end{tabular}

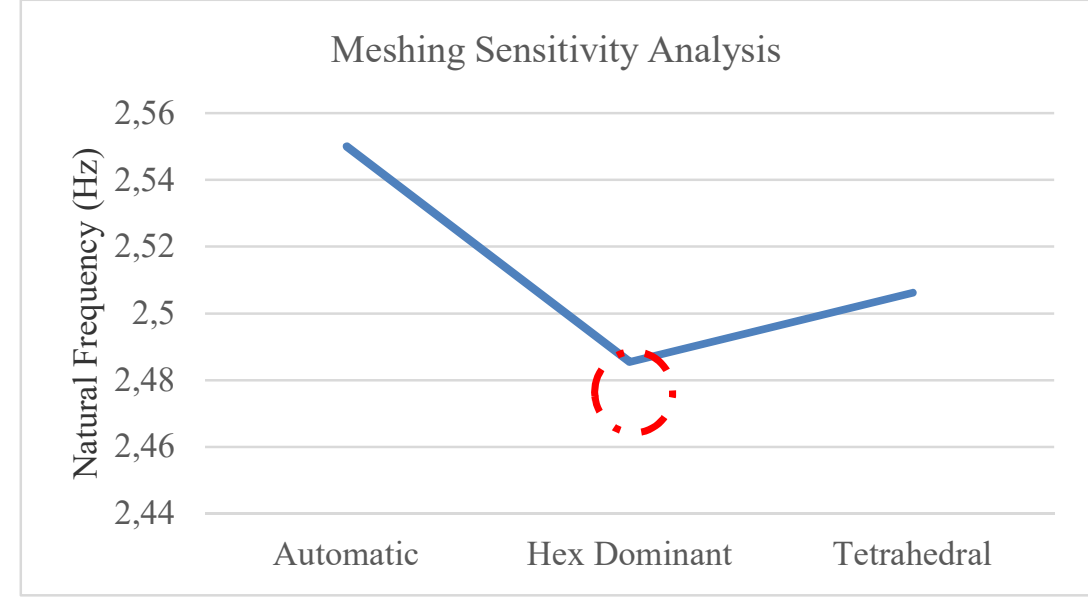

Fig. 4. Meshing sensitivity analysis of the power station structure

\subsection{Modal and Harmonic Responses of the Dam Power Station}

Figure 5 shows the meshed FE model of the real power station structure that has been developed using ANSYS software. As the result determined in the previous section, the meshing type for the simulation is set as tetrahedral and the element size used is between $1.0 \mathrm{~m}$ to $5.0 \mathrm{~m}$ per element according to complexity of the part. This resulting the total amount of 545269 nodes and 314981 tetrahedral dominant elements for the whole power station structure of the dam.

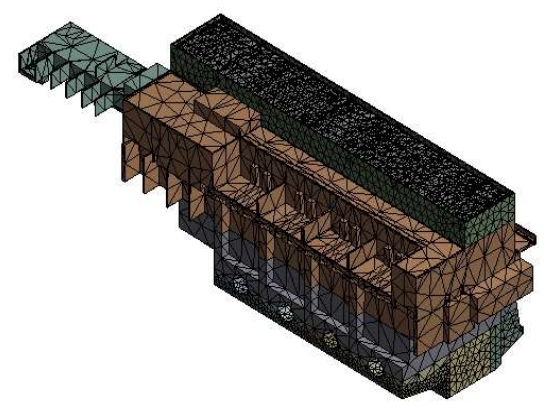

Fig. 5. Meshed FE model of the power station structure 
Table 4 shows the six most significant natural frequencies and mode shapes of the power station structure. It is clearly shown that, the $13^{\text {th }}$ mode shape affected the largest area of the power station structure with the natural frequency value of $9.3177 \mathrm{~Hz}$ and overall deflection value of $4.2572 \times 10^{-3} \mathrm{~m}$. This mode shape caused the most significant deflection at the upper part of the main power station structure and office complex. The $1^{\text {st }}, 3^{\text {rd }}, 10^{\text {th }}, 19^{\text {th }}$ and $26^{\text {th }}$ modes occurred at $2.6077 \mathrm{~Hz}, 5.4193 \mathrm{~Hz}, 8.3772 \mathrm{~Hz}, 10.166 \mathrm{~Hz}$ and $11.613 \mathrm{~Hz}$, respectively where at these natural frequencies and mode shapes, the deflection similarly occurred at the upper part of the main power station structure and office complex which lower value of deflection compared to the $13^{\text {th }}$ mode shape.

Table 4. Six most significant mode shapes and natural frequencies of the power station

\begin{tabular}{|c|c|c|c|}
\hline $\begin{array}{c}\text { Modes } \\
\text { No. }\end{array}$ & Mode Shapes & $\begin{array}{c}\text { Natural } \\
\text { Frequency }\end{array}$ & $\begin{array}{c}\text { Deflection } \\
\text { Values }\end{array}$ \\
\hline 1 & $2.6077 \mathrm{~Hz}$ & $1.891 \times 10^{-3} \mathrm{~m}$ \\
\hline 3 & & $5.4193 \mathrm{~Hz}$ & $2.2805 \times 10^{-3} \mathrm{~m}$ \\
\hline 10 & & $8.3772 \mathrm{~Hz}$ & $3.0838 \times 10^{-3} \mathrm{~m}$ \\
\hline 13 & & & \\
\hline
\end{tabular}




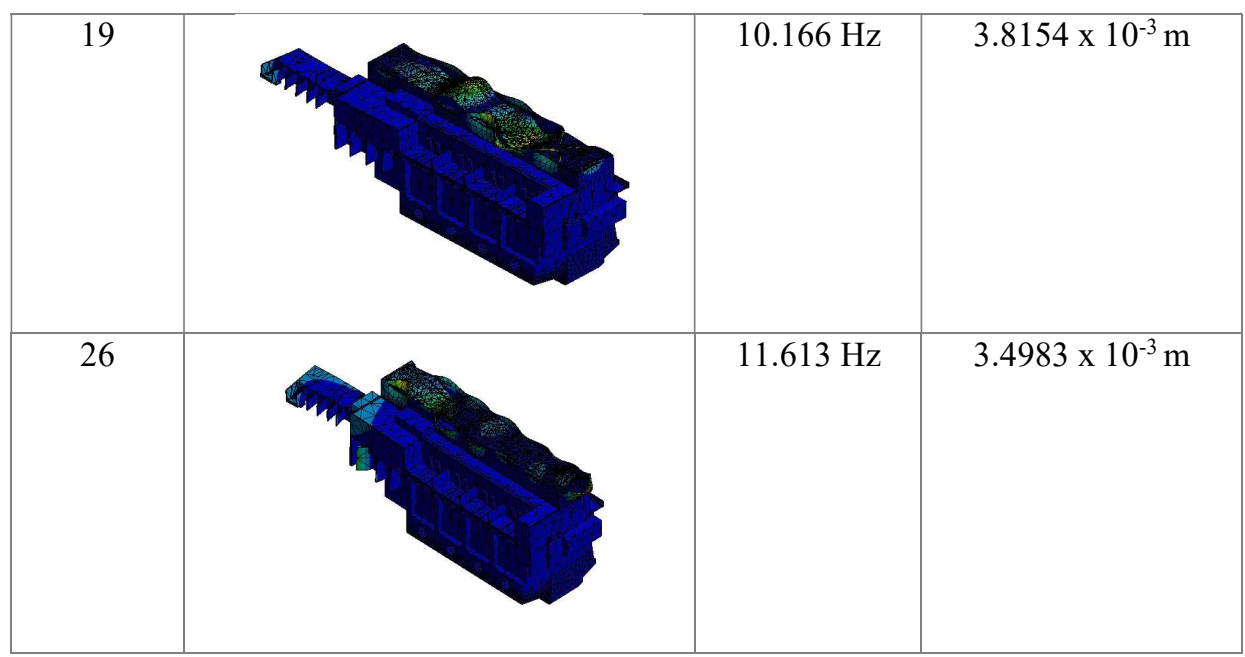

Table 5 shows the FRF results of the dam power station structure in $x, y$ and $z$ axis directions. From the graphs shown in Table 5, the highest natural frequency peak value occurred at $5.4 \mathrm{~Hz}$ in $z$ axis direction of the power station structure with maximum deflection value of $0.90361 \mathrm{~m}$. Whilst for $x$ and $y$ axes, the highest peak of natural frequencies occurred at $10.05 \mathrm{~Hz}$ and $10.2 \mathrm{~Hz}$, respectively with the maximum deflection value of $0.88256 \mathrm{~m}$ in $x$ axis direction and $0.78658 \mathrm{~m}$ in $y$ axis direction. All three maximum deflection occurred is referred to the highly bended mode shapes at the upper part of the power station structure as shown previously in Table 4. Any external induced vibration that coincides with these natural frequency values may destruct the structure of the dam power station due to resonance phenomenon.

Table 5. FRF graphs of the power station in $x, y$ and $z$ axis directions

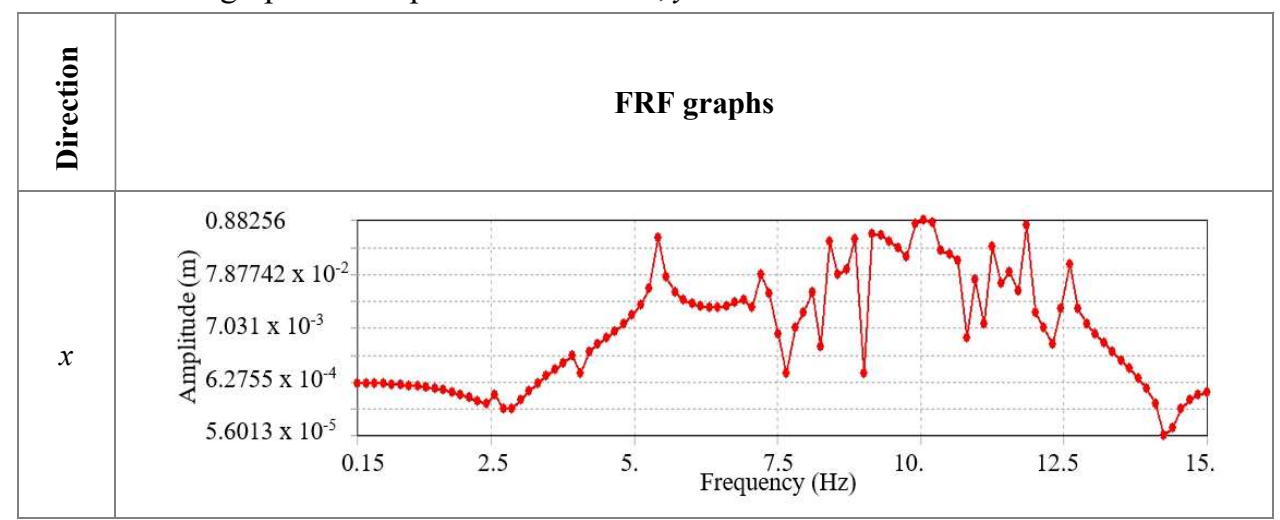




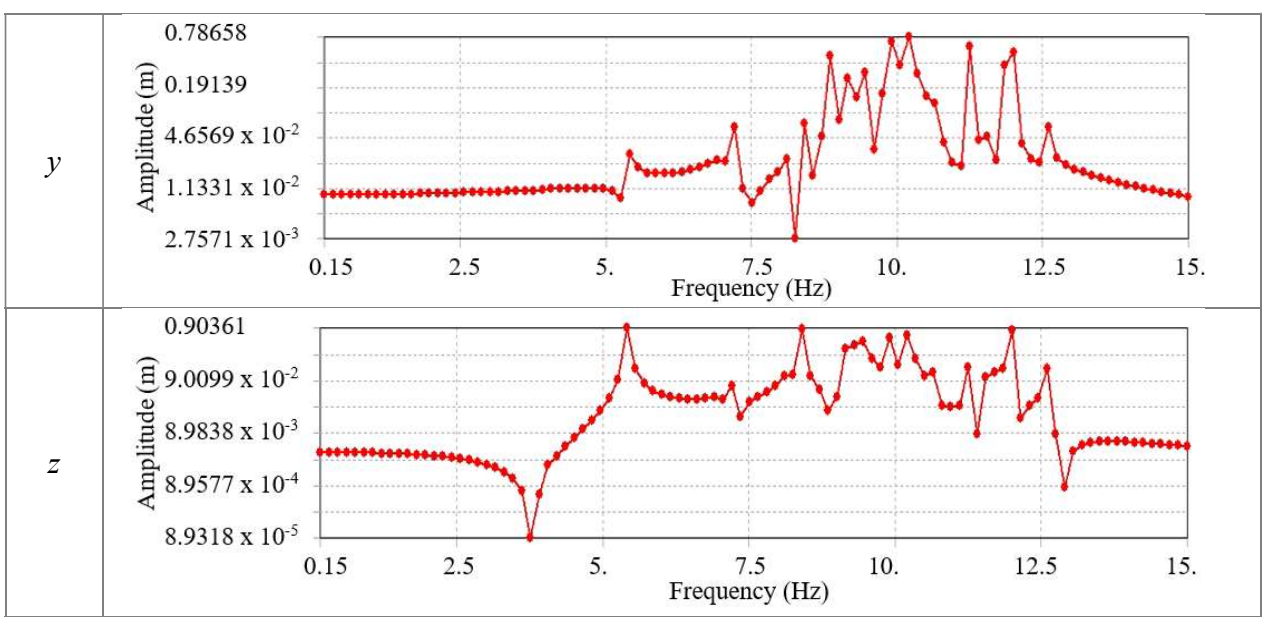

\section{CONCLUSION}

In this study, the vibration analysis of the Kenyir Dam power station structure in terms of modal and harmonic responses have been successfully carried out. From the results, several conclusions can be made as follows:

- The real scale 3D model of the Kenyir Dam power station structure has been developed in detail according to the as-built drawing of the dam.

- The optimum type of meshing has been found through meshing sensitivity analysis which is the hex dominant but due to the complexity of the structure, the modal analysis simulation is carried out using tetrahedral type of meshing.

- The modal analysis of the power station section has been performed where the $13^{\text {th }}$ mode shape shows the largest deformation area (highest deflection amplitude) of the power station structure at $9.3177 \mathrm{~Hz}$ of natural frequency.

- The harmonic analysis has been successfully accomplished and the result shows that, the highest natural frequency occurred at $5.4 \mathrm{~Hz}$ in $z$ axis direction with the maximum deflection value is $0.90361 \mathrm{~m}$. This value must be taken into consideration to avoid any resonance of the power station structure

\section{ACKNOWLEDGEMENTS}

The authors would like to acknowledge Uniten R\&D and Universiti Sains Malaysia for providing financial assistance through grant (203.PMEKANIK.6071370). 


\section{REFERENCES}

1. Kanazawa, K, Sawada, Y, Nagumo, H and Itoh, Y 2004. Earthquake Response Characteristics of Rock-Fill Dam With Asymmetrical Section in Dam Axis Direction. 13th World Conf. Earthq. Eng., No. 816.

2. Singh, VK, Chauhan, NS and Kushwaha, D 2015. An Overview of HydroElectric Power Plant. ISST J. Mech. Eng., vol. 6, No. 1, 59-62.

3. Ajibola, OOE, Ajala, OS, Akaanmu, JO and Balogun, OJ 2018. Improvement of Hydroelectric Power Generation Using Pumped Storage System. Niger. J. Technol., vol. 37, No. 1, 191-199.

4. Kulkarni, SR, Ukarande, SK and Jagtap, SA 2016. Dam Break Analysis - A Review. ISSN 2347 - 2812, vol. 4, No. 4, 31-35.

5. Thieffry, BP and Manager, LP 2010. Best of Both Worlds : Combining APDL with ANSYS Workbench for Structural Simulations. 48-50.

6. Bhashyam, GR 2002. ANSYS Mechanical-A Powerful Nonlinear Simulation Tool.

7. Elmenshawy, MRE 2015. Static And Dynamic Analysis of Concrete Gravity Dams. Tanta University.

8. Chopra, AK and Chakrabarti, P 1972The Earthquake Experience at Koyna Dam and Stresses in Concrete Gravity Dams. Earthq. Eng. Struct. Dyn.

9. Khosravi, S and Heydari, MM 2015. Design and Modal Analysis of Gravity Dams by Ansys Parametric Design Language. Walailak J. Sci. Technol., vol. 12, No. 2, 167-180.

10. Han, L and Hu, X 2017. SPH Modeling of Fluid-Structure Interaction. $12^{\text {th }}$ International SPHERIC Workshop.

11. Silveira, IV and Pedroso, LJ 2018. Analysis of Natural Frequencies and Modes of Vibration Involving Interaction Dam-Reservoir Foundation for Concrete Gravity Dams. Third Int. Dam World Conf.

12. Erhunmwun, I and Ikponmwosa, U 2017. Review on Finite Element Method. J. Appl. Sci. Environ. Manag., vol. 21, No. 5, 999-1002.

13. Chaphalkar, SP, Khetre, SN and Meshram, AM 2015. Modal Analysis of Cantilever Beam Structure Using Finite Element Analysis and Experimental Analysis. Am. J. Eng. Res., vol. 4, No. 10, 178-185.

14. Khan, IA and Awari, GK 2014. Analysis of Natural Frequency and Mode Shape of All Edge Fixed Condition Plate with Uncertain Parameters. Int. J. Innov. Res. Sci. Eng. Technol., vol. 3, No. 2, 9277-9284.

15. Sulaiman, MSA, Yunus, MA, Bahari, AR and Rani, MNA 2017. Identification of Damage Based on Frequency Response Function (FRF) Data. MATEC Web of Conferences, vol. 01025.

16. Dziedziech 2015. Time-Variant Frequency Response Function for Analysis of Time-Varying Mechanical Systems. vol. 34, No. 2, 29-33.

Editor received the manuscript: 12.08.2019 